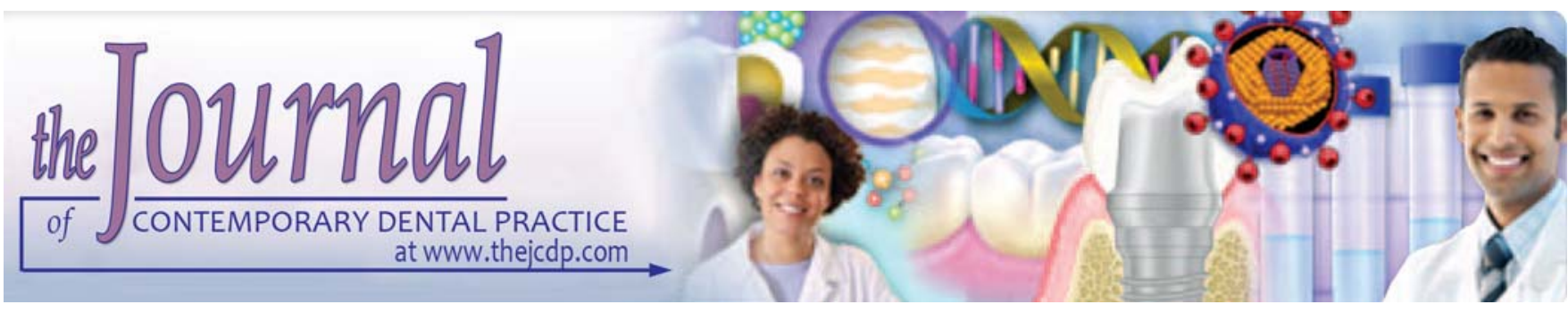

\title{
Alterations in Serum Lipid Profile Patterns in Oral Squamous Cell Carcinoma Patients
}

\author{
Gaurav Ghosh, Krithika M Jayaram, Rekha V Patil, Sangeeta Malik
}

\begin{abstract}
Aim: Altered lipid profile patterns have been associated with malignancies because lipids play a pivotal role in the maintenance of cell integrity. The present study evaluated alterations in serum lipid profile in oral squamous cell carcinoma patients as well as its association with the habit of tobacco consumption.
\end{abstract}

Materials and methods: The study included 30 oral squamous cell carcinoma patients, 20 patients with the habit of tobacco consumption and 20 controls. Serum lipids, including (i) total cholesterol, (ii) LDL cholesterol (LDLC), (iii) HDL cholesterol (HDLC), (iv) VLDL cholesterol (VLDLC) and (v) triglycerides, were analyzed by spectrophotometric kits.

Results: A significant decrease in serum total cholesterol (TC) levels, triglyceride levels ( $p=0.007, p=0.029$ respectively) were observed in oral squamous cell carcinoma patients as compared to the healthy control group. The mean serum HDLC levels $(p=0.003)$ were significantly lowered in the tobacco habituates when compared to the healthy controls. The mean serum total cholesterol levels were significantly lower in subjects with oral squamous cell carcinoma $(p=0.000)$ as compared to the tobacco habituates. Likewise, LDLC levels and TC:HDLC ratios ( $p=0.000$ and $p=0.000$ respectively) were significantly decreased in oral squamous cell carcinoma patients as compared to the tobacco habituates. Our data strengthens the evidence of an inverse relationship between serum lipid levels and oral squamous cell carcinoma.

Conclusion: The lower level of serum cholesterol and other lipid constituents in the patients is thought to be due to their increased usage by tumor cells for new membrane biogenesis.

Clinical significance: The lower serum lipid profile status serves as a useful indicator for gauging initial changes occurring in tumor cells. A detailed study of the cholesterol carrying lipoprotein transport mechanisms helps in better understanding of the underlying mechanisms of the regulation of serum cholesterol concentrations in cancer.

Keywords: High-density lipids, Low-density lipids, Very lowdensity lipids, Cholesterol, Triglycerides, Oral squamous cell carcinoma, Case control study.

How to cite this article: Ghosh G, Jayaram KM, Patil RV, Malik S. Alterations in Serum Lipid Profile Patterns in Oral Squamous
Cell Carcinoma Patients. J Contemp Dent Pract 2011;12(6): 451-456.

Source of support: Nil

Conflict of interest: None declared

\section{INTRODUCTION}

Oral squamous cell carcinoma is one of the most common malignancies in India, accounting for 30 to $40 \%$ of all cancers. Squamous cell carcinoma of the oral cavity is responsible for considerable morbidity and mortality in India, where 60,000 new cases of oral cancer are reported to occur every year. ${ }^{1}$

Lipids are major cell membrane components essential for various biological functions, including cell growth and division of normal and malignant tissues. Usefulness of variations in tissue/blood cholesterol levels in diagnosis and treatment of various diseases has been studied by several workers. It is believed that tobacco carcinogens induce generation of free radicals and reactive oxygen species, which are responsible for high rate of oxidation/ peroxidation of polyunsaturated fatty acids. This peroxidation further releases peroxide radicals. This affects essential constituents of the cell membrane and might be involved in carcinogenesis/tumorigenesis. Because of the lipid peroxidation, there is a greater utilization of lipids, including total cholesterol, lipoproteins and triglycerides for new membrane biogenesis. Cells fulfill these requirements either from circulation by synthesis through the metabolism or from degradation of major lipoprotein fractions, like VLDL, LDL or HDL. ${ }^{2}$

The present study was aimed at evaluating the serum lipid profile, including total cholesterol, high-density lipoprotein cholesterol (HDLC), low-density lipoprotein cholesterol (LDLC), very low-density lipoprotein cholesterol (VLDLC) and triglycerides in oral squamous 
cell carcinoma patients and studying its association with the habit of tobacco consumption.

\section{MATERIALS AND METHODS}

The study subjects comprised of three groups as follows:

1. Group 1: Healthy controls

2. Group 2: Tobacco habituates

3. Group 3: Subjects with oral squamous cell carcinoma.

\section{Method of Examination and Confirmation of Clinical Diagnosis}

Examination of the patients was carried out using a mouth mirror and probe under artificial light. The clinical photographs were obtained to complete the clinical records. Routine hematological examinations (to ascertain bleeding time, clotting time, fasting blood sugar levels, hemoglobin count and erythrocyte sedimentation rate) and blood pressure estimation were done for all subjects to rule out any systemic diseases.

\section{Collection of Venous Blood}

Fasting blood samples were collected under all aseptic precautions by vein puncture. 2 cc of venous blood was withdrawn with the help of a $2 \mathrm{ml}$ disposable syringe and a 24 gauge disposable needle, into plain vacuettes. These samples were allowed to clot for 30 minutes and then centrifuged for 15 minutes to get a clear serum sample which is separated from the clot and transferred to a disposable vial for assay. The estimation was performed within 3 hours of receiving the samples by using an appropriate kit (Genuine Biosystem) and quantitated for total serum cholesterol, LDL, VLDL, HDL and triglycerides using a computerized semiautomated biochemistry analyzer.

\section{Methods}

Serum cholesterol levels were estimated using cholesterol kits obtained from Genuine Biosystem, Chennai, India. Briefly, $10 \mu \mathrm{l}$ of plasma sample was mixed with $500 \mu \mathrm{l}$ of working reagent that contained cholesterol oxidase, cholesterol esterase, peroxidase, 4-aminophenazone, surfactant, phenol, buffer, preservatives and stabilizer. The mixture was incubated at $37^{\circ} \mathrm{C}$ for 10 minutes and absorbance was read at $505 \mathrm{~nm}$.

Serum HDL cholesterol levels were also estimated using cholesterol kits. Briefly, $10 \mathrm{ml}$ plasma sample was mixed with $0.3 \mathrm{ml}$ precipitating reagent (PEG 6000, stabilizer and preservative), followed by 10 minutes incubation at room temperature. The mixture was centrifuged at $2000 \mathrm{rpm}$ for 15 minutes. The supernatant obtained was mixed with working cholesterol reagent. After incubation of 10 minutes at $37^{\circ} \mathrm{C}$, absorbance was read at $505 \mathrm{~nm}$.

Quantitative serum triglyceride levels were estimated using reagent kits. Briefly, $10 \mu$ plasma sample was mixed with $1000 \mu \mathrm{l}$ of triglycerides assay reagent containing pipes buffer, lipase, 4-chlorophenol, Mg ion, ATP, lipase, peroxidase, glycerol kinase, sodium azide, 4-aminoantipyrene, glycerol3-phosphate oxidase and detergents. The mixture was then incubated for 10 minutes at $37^{\circ} \mathrm{C}$ and absorbance was read at $505 \mathrm{~nm}$.

VLDLC and LDLC levels were calculated as shown below:

VLDLC $=$ Triglycerides $/ 5$

LDLC $=$ Total cholesterol $-($ VLDLC $)-($ HDLC $)$.

\section{Statistical Analysis}

The statistical analysis consisted of the student's t-test, which was performed to compare mean values of the parameters. The SPSS 15.0 for Windows was used to ascertain the results. $\mathrm{p}$-value $<0.05$ was considered to be statistically significant.

\section{RESULTS}

\section{Comparison of Serum Lipid Profiles between Groups 1 and 3}

The mean serum lipid profiles of healthy controls and oral squamous cell carcinoma patients, at the time of diagnosis, are represented in Table 1 and Graph 1. A significant decrease in serum total cholesterol (TC) levels, triglyceride levels ( $p=0.007, p=0.029$ respectively) and a nonsignificant decrease in the serum low-density lipid cholesterol (LDLC) levels, high-density lipid cholesterol (HDLC) levels and very low-density lipid cholesterol (VLDLC) levels ( $p=0.121, p=0.079$ and $p=0.101$ respectively) were observed in oral squamous cell carcinoma patients as compared to the healthy control group. The TC:HDL ratios were non-significantly increased in oral squamous cell carcinoma patients as compared to the healthy control group.

\section{Comparison of Serum Lipid Profile between Groups 1 and 2}

The serum lipid levels between tobacco consumers and healthy controls were compared (Table 2 and Graph 2). The subjects consuming tobacco showed higher levels of mean serum total cholesterol $(p=0.607)$ and mean serum LDLC ( $p=0.125$ ) than the healthy controls. However, this data was not statistically significant. The mean serum HDLC levels ( $p=0.003$ ) were significantly lowered in the tobacco 


\begin{tabular}{|c|c|c|c|c|c|}
\hline & Groups & $N$ & Mean & Std. deviation & Sig. ( $p$-value) \\
\hline \multirow[t]{2}{*}{ TC } & OSCC group & 30 & 161.896 & 26.202 & 0.007 "S" \\
\hline & HC group & 04 & 201.000 & 16.573 & \\
\hline \multirow[t]{2}{*}{ TGL } & OSCC group & 30 & 124.379 & 50.122 & 0.029 “S" \\
\hline & HC group & 04 & 188.750 & 72.789 & \\
\hline \multirow[t]{2}{*}{ HDL } & OSCC group & 30 & 39.724 & 7.864 & 0.079 "NS" \\
\hline & HC group & 04 & 47.250 & 6.946 & \\
\hline \multirow[t]{2}{*}{ LDL } & OSCC group & 30 & 99.069 & 20.566 & 0.121 "NS" \\
\hline & HC group & 04 & 116.000 & 12.027 & \\
\hline \multirow[t]{2}{*}{ VLDL } & OSCC group & 30 & 24.413 & 14.819 & 0.101 "NS" \\
\hline & HC group & 04 & 37.750 & 14.568 & \\
\hline \multirow[t]{2}{*}{ TC/HDL } & OSCC group & 30 & 4.100 & 0.600 & 0.871 "NS" \\
\hline & HC group & 04 & 4.050 & 0.100 & \\
\hline
\end{tabular}

HC: Healthy controls with no habit of tobacco consumption, OSCC: Oral squamous cell carcinoma subjects, S: Statistically significant data, NS: Statistically not significant data

\begin{tabular}{|c|c|c|c|c|c|}
\hline & Groups & $N$ & Mean & Std. deviation & Sig. (p-value) \\
\hline \multirow[t]{2}{*}{ TC } & TH group & 19 & 209.947 & 32.975 & 0.607 "NS" \\
\hline & HC group & 04 & 201.000 & 16.573 & \\
\hline \multirow[t]{2}{*}{ TGL } & TH group & 19 & 149.894 & 67.468 & 0.313 "NS" \\
\hline & HC group & 04 & 188.750 & 72.789 & \\
\hline \multirow[t]{2}{*}{ HDL } & $\mathrm{TH}$ group & 19 & 34.421 & 6.793 & 0.003 “S” \\
\hline & HC group & 04 & 47.250 & 6.946 & \\
\hline \multirow[t]{2}{*}{ LDL } & TH group & 19 & 144.263 & 34.341 & 0.125 "NS" \\
\hline & HC group & 04 & 116.000 & 12.027 & \\
\hline \multirow[t]{2}{*}{ VLDL } & TH group & 19 & 30.000 & 13.585 & 0.317 "NS" \\
\hline & HC group & 04 & 37.750 & 14.568 & \\
\hline \multirow[t]{2}{*}{$\mathrm{TC} / \mathrm{HDL}$} & TH group & 19 & 6.152 & 0.823 & 0.000 "S" \\
\hline & HC group & 04 & 4.050 & 0.100 & \\
\hline
\end{tabular}

$\mathrm{HC}$ : Healthy controls with no habit of tobacco consumption, TH: Individuals with habit of tobacco consumption, S: Statistically significant data, NS: Statistically not significant data

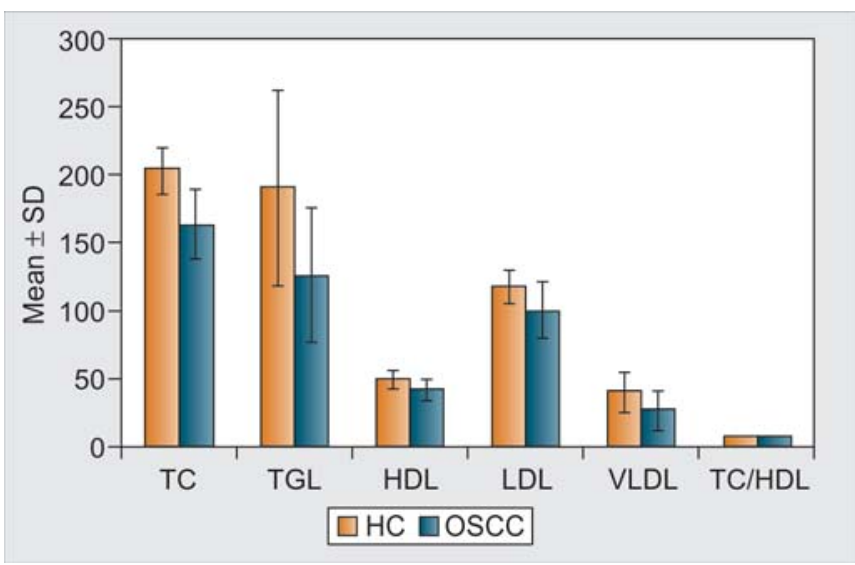

Graph 1: Comparison of serum lipid profile patterns between oral squamous cell carcinoma patient group and healthy control group

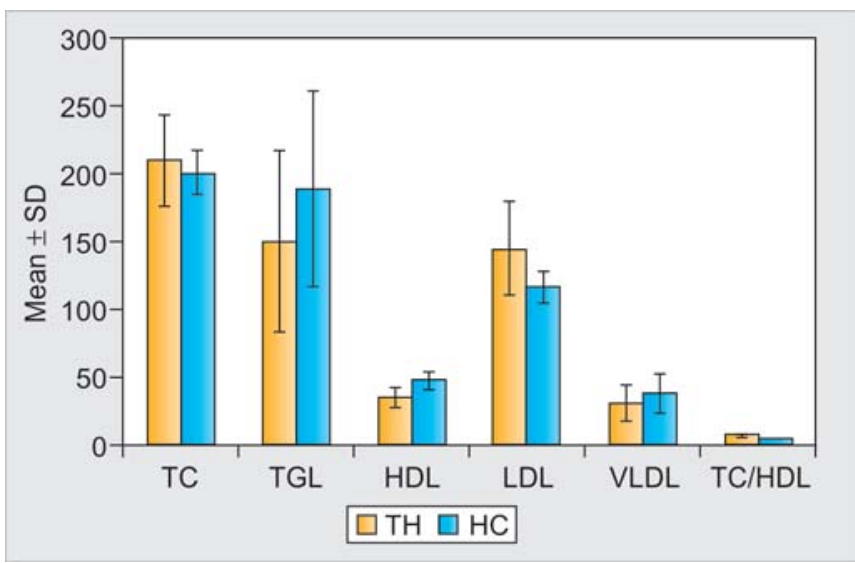

Graph 2: Comparison of serum lipid profile patterns between tobacco habituate group and healthy control group

\section{Comparison of Serum Lipid Profiles between Groups 2 and 3}

The serum lipid levels in oral squamous cell carcinoma patients were also compared with the tobacco habituates, as depicted in Table 3 and Graph 3. The mean serum total 


\begin{tabular}{|c|c|c|c|c|c|}
\hline & Groups & $N$ & Mean & Std. deviation & Sig. (p-value) \\
\hline \multirow[t]{2}{*}{ TC } & TH group & 19 & 209.947 & 32.975 & 0.000 “S" \\
\hline & OSCC group & 30 & 161.896 & 26.202 & \\
\hline \multirow[t]{2}{*}{ TGL } & TH group & 19 & 149.894 & 67.468 & 0.140 "NS" \\
\hline & OSCC group & 30 & 124.379 & 50.122 & \\
\hline \multirow[t]{2}{*}{ HDL } & TH group & 19 & 34.421 & 6.793 & 0.020 “S" \\
\hline & OSCC group & 30 & 39.724 & 7.864 & \\
\hline \multirow[t]{2}{*}{ LDL } & TH group & 19 & 144.263 & 34.341 & 0.000 "S" \\
\hline & OSCC group & 30 & 99.069 & 20.566 & \\
\hline \multirow[t]{2}{*}{ VLDL } & TH group & 19 & 30.000 & 13.585 & 0.194 "NS" \\
\hline & OSCC group & 30 & 24.413 & 14.819 & \\
\hline \multirow[t]{2}{*}{$\mathrm{TC} / \mathrm{HDL}$} & TH group & 19 & 6.152 & 0.823 & 0.000 "S" \\
\hline & OSCC group & 30 & 4.100 & 0.600 & \\
\hline
\end{tabular}

TH: Individuals with habit of tobacco consumption, OSCC: Oral squamous cell carcinoma patients, S: Statistically significant data, NS: Statistically not significant data

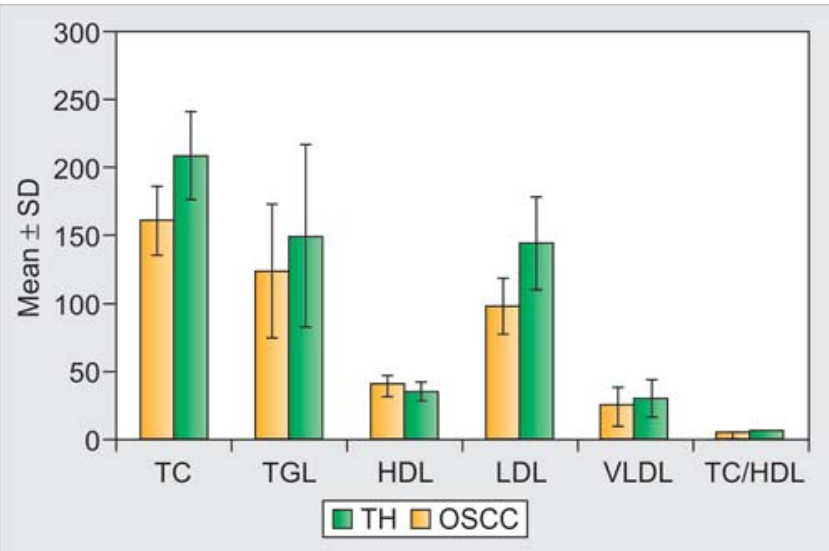

Graph 3: Comparison of serum lipid profile patterns between oral squamous cell carcinoma patient group and tobacco habituate group

cholesterol levels were significantly lower in subjects with oral squamous cell carcinoma ( $\mathrm{p}=0.000)$ as compared to the tobacco habituates. Likewise, LDLC levels and TC:HDLC ratios ( $\mathrm{p}=0.000$ and $\mathrm{p}=0.000$ respectively $)$ were significantly decreased in oral squamous cell carcinoma patients as compared to the tobacco habituates. However, a significant increase in the mean serum HDLC levels was noted in the oral squamous cell carcinoma patients as compared to the tobacco habituates $(p=0.020)$. A non-significant decrease in the mean serum VLDLC and triglyceride levels ( $\mathrm{p}=0.194, \mathrm{p}=0.140$ respectively) was noted in the oral squamous cell carcinoma patients as compared to the tobacco habituates.

\section{DISCUSSION}

Cholesterol and triglycerides are important lipid constituents of the cell and essential to carry out several vital physiological functions.

In some malignant diseases, serum cholesterol undergoes early and significant changes. Low levels of serum cholesterol in the proliferating tissues and in blood compartments could be due to the process of carcinogenesis. However, earlier studies have reported that hypolipidemia may result due to the direct lipid lowering effect of tumor cells or some secondary malfunction of the lipid metabolism or secondary to antioxidant vitamins. ${ }^{1-5}$

Schatzkin ${ }^{6}$, Chyou ${ }^{7}$, Patel PS ${ }^{2}$, have observed an inverse trend between lower serum cholesterol and head-neck as well as esophageal cancers. The results are strengthened by our study which shows significantly decreased total serum cholesterol and triglyceride levels $(\mathrm{p}=0.007, \mathrm{p}=0.029$ respectively) in oral squamous cell carcinoma patients as compared to the healthy controls. A nonsignificant decrease in the serum high-density lipid cholesterol (HDLC) levels, low-density lipid cholesterol (LDLC) levels and very lowdensity lipid cholesterol (VLDLC) levels $(p=0.079, p=0.121$, $\mathrm{p}=0.079$ and $\mathrm{p}=0.101$ respectively) were observed in oral squamous cell carcinoma patients as compared to the healthy control group. This is thought to be a consequence of disease that is mediated by utilization of cholesterol for membrane biogenesis. This correlates with the study carried out by Patel PS. ${ }^{2}$

Alexopoulos ${ }^{8}$ reported a nonsignificant difference in serum triglycerides between controls and patients. While others have observed elevated triglycerides levels in cancer patients. ${ }^{9,10}$

In the present study, the levels of the serum lipids in tobacco consumers was compared with serum lipid profile of healthy controls. The tobacco consumer group showed nonsignificant higher levels of serum total cholesterol $(p=0.607)$ and serum LDLC levels $(p=0.125)$ and a nonsignificant decrease in serum triglyceride levels and VLDLC levels ( $\mathrm{p}=0.313$ and $\mathrm{p}=0.317$ respectively) than the healthy controls. The mean serum HDLC levels $(p=0.003)$ were significantly lowered in the tobacco consumer group when compared to healthy controls. This is in accordance with the study carried out by Mallika et al. ${ }^{11}$ 
Further, the present study compared the mean serum lipid profiles between the oral squamous cell carcinoma patient group and the tobacco consumer group. The mean serum total cholesterol levels, LDLC levels and TC:HDLC ratios $(\mathrm{p}=0.000, \mathrm{p}=0.000$ and $\mathrm{p}=0.000$ respectively) were significantly lower in patients with oral squamous cell carcinoma as compared to the tobacco consumer group. However, a significant increase in the mean serum HDLC levels was noted in the oral squamous cell carcinoma patients as compared to the tobacco consumer group $(p=0.020)$. A nonsignificant decrease in the mean serum VLDLC and triglyceride levels $(\mathrm{p}=0.194, \mathrm{p}=0.140$ respectively) was noted in the oral squamous cell carcinoma patients as compared to the tobacco consumer group. This can probably be attributed to reverse cholesterol transport, a key component of cholesterol homeostasis. ${ }^{12-15}$

The results of this study add to the evidence of an inverse relationship between serum lipid profile and oral squamous cell carcinoma. The lower levels of serum cholesterol and other lipid constituents in patients of oral squamous cell carcinoma might be due to their increased utilization by tumor cells for new membrane biogenesis and may serve as a useful indicator for initial changes occurring in tumor cells. Tobacco carcinogens induce generation of free radicals and reactive oxygen species which are responsible for the high rate of peroxidation of polyunsaturated fatty acids. This affects essential constituents of the cell membrane and may be involved in carcinogenesis. Lipid peroxidation leads to greater utilization of lipids, including total cholesterol, lipoproteins and triglycerides for new membrane biogenesis. Cells fulfill these requirements either from the circulation, by synthesis through the metabolism or from the degradation of major lipoprotein fractions, like VLDL, LDL or HDL.

\section{CONCLUSION}

From the present study, it is evident that there are definite underlying biochemical alterations in the serum of patients with oral squamous cell carcinoma, when compared with serum levels of healthy individuals. The lower levels of serum cholesterol and other lipid constituents in the patients are thought to be due to their increased usage by tumor cells for new membrane biogenesis.

\section{CLINICAL SIGNIFICANCE}

The lower serum lipid profile pattern status may serve as a useful indicator for gauging initial changes occurring in malignant cells. A detailed study of the cholesterol carrying lipoprotein transport mechanisms and the efficiency of the receptor system may enhance better understanding of the underlying mechanisms of the regulation of serum cholesterol concentrations in cancer.

Hence, a further study in this field is to be attempted for better understanding which will help in elaboration and early diagnosis of oral squamous cell carcinoma.

\section{REFERENCES}

1. Manoharan S, Kolanjiappan K, Suresh K, Panjamurthy K. Lipid peroxidation and antioxidants status in patients with oral squamous cell carcinoma. Indian J Med Res December 2005; 122:529-34.

2. Patel PS, Shah MH, Jha FP, Raval GN, Rawal RM, Patel MM, et al. Alterations in plasma lipid profile patterns in head and neck cancer and oral precancerous conditions. Indian Journal of Cancer 2004;41(1):25-31.

3. Eichholzer Monika, Stähelin Hannes B, Gutzwiller Felix, Lüdin Eric, Bernasconi Florence. Association of low plasma cholesterol with mortality for cancer at various sites in men: 17-year followup of the prospective Basel study. Am J Clin Nutr 2000;71: 569-74.

4. Choi MA, Kim BS, Yu R. Serum antioxidative vitamin levels and lipid peroxidation in gastric carcinoma patients. Cancer Lett 1999;136:89-93.

5. Kark JD, Smith AH, Hames CG. Serum retinol and the inverse relationship between serum cholesterol and cancer. Br Med J 1982;284:152-54. dian J Biochem Biophys 1999;36:44-50.

6. Schatzkin A, Hoover RN, Taylor PR, Ziegler RG, Carter CL, Albanes D. Site-specific analysis of total serum cholesterol and incident cancers in the National Health and Nutrition Examination Survey I epidemiologic follow-up study. Cancer Res 1988;48:452-58.

7. Chyou PH, Nomura AM, Stemmermann GN, Kato I. Prospective study of serum cholesterol and site-specific cancers. J Clin Epidemiol 1992;45:287-92.

8. Alexopoulos CG, Blatsios B, Avgerinos A. Serum lipids and lipoprotein disorders in cancer patients. Cancer 1987;60: 3065-70.

9. Halton JM, Nazir DJ, McQueen MJ, Barr RD. Blood lipid profiles in children with acute lymphoblastic leukemia. Cancer 1998;83:379-84.

10. Favrot MC, Dellamonica C, Souillet G. Study of blood lipids in 30 children with a malignant hematological disease or carcinoma. Biomed. Pharmacother 1984;38:55-59.

11. Mallika R, Prasad Rajendra N, Pugalendi KV. Influence of habits on masons' blood cholesterol. Indian J Physiol Pharmacol 2003;47(4):429-34.

12. Martin David W Jr, Mayes Peter A, Rodwell Victor W, Granner Daryl K. Harper's review of biochemistry (20th ed). Lange Maruzen publications 1986.

13. Vasudevan DM, Sreekumari S. Textbook of biochemistry for medical students (5th ed). Jaypee publications 2007.

14. Marshall William J, Bangert Stephen K. Clinical chemistry (5th ed). Mosby 2005.

15. Harvey Richard A, Champe Pamela C. Lippincott's illustrated reviews in biochemistry (3rd ed). Lippincott Williams and Wilkins publications 1984. 


\section{ABOUT THE AUTHORS}

\section{Gaurav Ghosh (Corresponding Author)}

Assistant Professor, Department of Oral Pathology and Microbiology Sri Rajiv Gandhi College of Dental Sciences, Bengaluru, Karnataka India, e-mail: drgauravghosh@gmail.com

\section{Krithika M Jayaram}

Consultant and Private Practitioner, Department of Orthodontics Quintessence Dental Solutions, Bengaluru, Karnataka, India

\section{Rekha V Patil}

Professor and Head, Department of Oral Pathology and Microbiology Sri Rajiv Gandhi College of Dental Sciences, Bengaluru, Karnataka India

\section{Sangeeta Malik}

Professor, Department of Oral Pathology and Microbiology Sri Rajiv Gandhi College of Dental Sciences, Bengaluru, Karnataka India 